\title{
Dextran coating on and among fibers of polymer sponge scaffold for osteogenesis by bone marrow cells in vivo
}

\author{
Masataka Yoshikawa ${ }^{1,2}$, Norimasa Tsuji ${ }^{1}$, Hideyuki Kakigi ${ }^{1}$, Takayoshi Yabuuchi ${ }^{1}$, \\ Yasunori Shimomura $^{1}$, Hiroyuki Hayashi ${ }^{1}$, Hajime Ohgushi ${ }^{2}$ \\ ${ }^{1}$ Department of Endodontics, Osaka Dental University, Osaka, Japan; \\ ${ }^{2}$ Tissue Engineering Research Group, Health Research Institute, National Institute of Advanced, Industrial Science and Technology, \\ Amagasaki, Japan. \\ Email: yosikawa@cc.osaka-dent.ac.jp
}

Received 25 May 2010; revised 8 June 2010; accepted 20 June 2010.

\begin{abstract}
Although hydroxyapatite is commonly used as a scaffold for bone regeneration, sponges may be suitable because of the adaptability to the defect. To use as a scaffold, the fiber of sponge would be coated with any adhesive to storage stem cells in the sponges. Fiber in the structure of commercially available sponges was coated by immersion in dextran solution and air dried. After seeding of rat bone marrow cells (rBMCs), the sponges were implanted subcutis of rats for estimate osteogenesis in vivo. The level of osteocalcin was $25.28 \pm 5.71 \mathrm{ng} / \mathrm{scaffold}$ and that of Ca was $129.20 \pm$ $19.69 \mu \mathrm{g} / \mathrm{scaffold}$. These values were significantly higher than those in sponges without dextran coating $(p<$ 0.01). It was thought that $\mathrm{rBMCs}$ could be stored on the shelf by dextran deposition in the fiber of the sponge. In vivo examination, dextran induced osteogenesis by rBMCs in many spaces in the inner structure of the sponge.
\end{abstract}

Keywords: Dextran; Cell Adhesion; Scaffold; Bone Marrow Cells; Osteogenesis

\section{INTRODUCTION}

A part or total tooth regeneration has been studied by many researchers [1-5]. In a basic study for tooth regeneration, it was shown that stem cells were detected in the tooth pulp [6]. And it was shown in the report that the stem cells differentiated to osteoblasts, chondrocytes, adipocytes or neurocytes. Development of the removed tooth germ to mature tooth was also attempted in vitro [7]. However, tooth regeneration by tissue engineering is particularly difficult because the constitution and configuration of a tooth is complex. Odontoblasts, ameloblasts and cement blasts will be required for tooth regeneration. Methods to isolate these cells from tissue or technique for differentiation and induce these blast cells from stem cells are not still established. This may be one of the reasons that tooth regeneration is not realized. Restoration of partial defect of the tooth or reproduction of the whole tooth that had been missed for any reason should be a definitive goal of the regenerative therapy in the dentistry. Also, for regeneration of tooth, isolation from the tissue of odontoblasts, ameloblasts and cementoblasts, and induction of differentiation from stem cells to these blast cells would be required. However, these methods have not yet been established.

It is well-known that bone consists of an apatite structure like dentine. Furthermore, osteocalcin which should be synthesized by osteoblasts is present in dentine as calcium-binding protein $[8,9]$. Therefore, for the restoration of teeth, a method of substituting bone which resembles dentine in properties should be established. For the regeneration of tooth or bone with a three-dimensional structure, a scaffold for proliferation and differentiation of bone marrow stem cells and osteogenesis is required. Sufficient resistance to load in the living body is required for regenerated hard tissue.

The morphology of the scaffold should be easily modifiable in order to apply the technique to any configuration of defects. The intensity of the sponge as a scaffold is extremely low, but modification of the shape is easy. Polyvinyl alcohol (PVA) sponge with bone marrow cells was used for bone regeneration in the defective part of the bone [10]. In this study, commercially available polyvinyl formal (PVF) sponge was selected as the scaffold. PVF sponge consists of PVA cross-linked construction by formalin. Stem cells must attach to the structure of the scaffold to induce osteogenesis by the cells in a porous scaffold $[11,12]$. However, the sponge is inappropriate for keeping cells because of the fibrous construction. One of the methods for seeding many cells to attach in the pores of scaffold is coating with a 
chemical substance that promotes cell adhesion on the scaffold [13]. Dextran, which has superior biocompatibility [14], is a natural polymer with linkage of a large number of D-glucose, and is a kind of polysaccharide existing in extracellular matrix. Dextran promotes adhesion between protein and cells [15].

This experiment investigated the effect of dextran to induce stem cell differentiation in dextran-coated PVF sponge. To confirm the effects of dextran and the availability the PVF sponge as a scaffold, coating of a PVF sponge with dextran was accomplished by immersion in dextran solution and in vivo examinations were performed.

\section{MATERIALS AND METHODS}

\subsection{Experimental Animals}

In this study, 6- and 7-week-old male Fischer 344 rats (CLEA Japan Inc., Tokyo, Japan) were used. The Animal Welfare Committee of Osaka Dental University approved the experimental procedures regarding use and care of animals in this study. This study was performed under the Guidelines for Animal Experimentation at Osaka Dental University.

\subsection{Rat Bone Marrow Cell (rBMC) Isolation}

rBMCs were obtained from the bone shaft of femora of six 6-week-old male Fischer 344 rats after euthanasia by intraperitoneal overdose of sodium pentobarbital (Dainippon-Sumitomo Pharmaceutical Co., Ltd., Osaka, Japan) essentially according to the methods described in previous reports [16,17] with minimal modification. Both ends of the femur were cut off at the epiphysis and bone marrow was flushed out with $10 \mathrm{ml}$ of minimum essential medium (MEM: Nakalai Tesque Inc., Kyoto, Japan) expelled from a syringe through a 21 -gauge needle.

\subsection{Primary Culture for Preparing rBMCs Suspension}

rBMCs in $10 \mathrm{ml}$ of MEM were removed in a cell culture flask (T75: BD Biosciences, MA, USA). For primary culture, MEM supplemented with $15 \%$ fetal bovine serum (FBS: JRH Biosciences, KS, USA) and antibiotics (100 units $/ \mathrm{ml}$ penicillin, $100 \mu \mathrm{g} / \mathrm{ml}$ streptomycin, and $0.25 \mu \mathrm{g} / \mathrm{ml}$ amphotericin B; Sigma Chemical Co., MO, USA) was prepared. Primary culture was performed for 1 week in $\mathrm{T} 75$ in $5 \% \mathrm{CO}_{2}$ and $95 \%$ relative humidity at $37^{\circ} \mathrm{C}$ in an incubator. The culture medium was renewed twice.

After primary culture, rBMCs in T75 culture flask were washed three times using phosphate buffer solution without $\mathrm{Ca}^{2+}$ and $\mathrm{Mg}^{2+}$ (PBS (-): Nakalai Tesque Inc.) and the cells were isolated from the bottom of T75 flask with trypsin-EDTA $(0.5 \mathrm{mg} / \mathrm{ml}$ trypsin and $0.53 \mu \mathrm{mol}$ EDTA: Nakalai Tesque Inc.) solution. Harvested cells were re-suspended in culture medium at $1 \times 10^{7} \mathrm{cells} / \mathrm{ml}$ concentration.

\subsection{Dextran Coating of Polyvinyl Formal (PVF) Sponge and rBMCs Seeding in the Sponges}

PVF sponges made by formalization of polyvinyl alcohol were generously donated by Ione (Osaka, Japan). PVF sponges with a cubic configuration $(5 \times 5 \times 5 \mathrm{~mm})$ for use in this study were obtained by cutting from a sheet. Pores were $130 \mu \mathrm{m}$ diameter on average. The PVF sponges were sterilized in ethylene oxide gas before use.

Dextran with $10 \mathrm{kDa}$ of molecular weight was purchased from Sigma-Aldich (MO, USA) and dissolved at $2 \mathrm{~g} / \mathrm{dl}$ concentration in ultra purified water. The liquid was sterilized by filtration $(0.22 \mu \mathrm{m})$ (Millex ${ }^{\mathbb{B}}$ : Milipore Japan, Tokyo, Japan). The sponges were immersed in dextran solution for 24 hours. The sponges used as a control were immersed in ultra purified water. The sponges were air-dried under radiation with ultraviolet light. Each of the PVF sponges with and without immersion in dextran solution were respectively seeded with $1 \times 10^{6}$ rBMCs in a $0.1 \mathrm{ml}$ cell suspension and were incubated for 3 hours in $5 \% \mathrm{CO}_{2}$ and $95 \%$ relative humidity at $37^{\circ} \mathrm{C}$ to promote cell adhesion in the sponges.

The micro structures of PVF sponges with and without immersion in dextran solution were observed by scanning electron microscopy (SEM, JSM 5400: JEOL DATUM Ltd., Tokyo, Japan). For SEM confirmation of whether the dextran coating on sponge fiber would be preserved during rBMCs seeding and subcutaneous implantation, sponges that had been immersed in dextran solution were stored in MEM for 4 weeks in $5 \% \mathrm{CO}_{2}$ and $95 \%$ relative humidity at $37^{\circ} \mathrm{C}$.

\subsection{Dorsal Subcutaneous Implantation of PVF Sponge with rBMCs}

For in vivo osteogenesis in PVF scaffolds, six of 7 week-old male Fischer 344 rats were used. Under general anaesthesia with intra-peritoneal injection of 0.04 $\mathrm{mg} / \mathrm{g}$ body weight of sodium pentobarbital, the backs of rats were shaved and disinfected with povidone iodine (Isodine $^{\circledR}$ : Meiji Seika Kaisha Ltd., Tokyo, Japan). The dorsal skin of the rat was incised close to the scapula on both sides across the vertebra at right angles and subcutaneous pockets were made using a mucosal raspatory. All rats were respectively implanted with four scaffolds in individual subcutaneous pockets alongside the vertebra. Two scaffolds without dextran coating but with rBMCs seeding were inserted in the left subcutaneous 
pocket of three rats and the other two with dextran coated and rBMCs seeding were inserted in the right side of the other three rats. The incised wounds were sutured, and adhesive (Aron alpha ${ }^{\circledR}$ : Toa-gosei Co., Ltd., Tokyo, Japan) was applied over the wounds. Implanted scaffolds were removed from the dorsal subcutaneous tissue of the rats 4 weeks postoperatively after euthanasia by intraperitoneal injection of excessive dose of sodium pentobarbital.

\subsection{Histological Examination of Osteogenesis in Implanted Scaffolds}

Three of each removed scaffold with or without dextran coating and with rBMCs seeding were fixed in $10 \%$ buffered formalin solution ( $\mathrm{pH}$ 7.2). Specimens were decalcified in $10 \%$ formic acid solution for two days, embedded in paraffin, and $6 \mu \mathrm{m}$ serial sections were made. All sections were stained with hematoxylin-eosin and examined under an optical microscope.

\subsection{Immunochemical and Biochemical Examination of Osteogenesis in Implanted Scaffolds}

The other remaining sponges removed from rat subcutaneous tissue were frozen in liquid nitrogen and crushed respectively using a Mixer Mill (MM 301: Retsch Co., Ltd., Tokyo, Japan). The crushed samples were respectively added to $1 \mathrm{ml}$ of buffer solution ( $\mathrm{pH}$ 7.4) consisting of $10 \mathrm{mM}$ Tris- $\mathrm{HCl}, 1 \mathrm{mM}$ EDTA and the $100 \mathrm{mM}$ $\mathrm{NaCl}$. The cells in the solution were sonicated for 30 seconds at $3^{\circ} \mathrm{C}$ (BIORUPTOR UCW-201: Tosho Electric Co., Ltd., Tokyo, Japan). The samples were centrifuged for 1 minute at $16,000 \times \mathrm{g}$. The supernatants were used for quantitative analysis of osteocalcin (Rat Osteocalcin ELISA kit DS ${ }^{\circledR}$; DS Pharma Biomedical Co., Ltd., Osaka, Japan). Then, $1 \mathrm{ml}$ of formic acid was individually added to each precipitation and samples were decalcified for 72 hours for analyze calcium quantity in each sponge using Calcium-E test WAKO ${ }^{\circledR}$ (Wako Pure Chemical Co. Inc., Osaka, Japan).

Data were presented as mean \pm standard deviations. Statistical comparisons between the mean values of osteocalcin in implanted scaffolds were performed using two-way unrepeated ANOVA followed by post hoc analysis using Tukey-Kramer's test. Differences of $p<$ 0.01 were considered significant.

\section{RESULTS}

\subsection{SEM Examination of PVF Sponges with and without Immersion in Dextran Solution}

The SEM image of the PVF sponge without immersion in dextran solution showed reticular configuration as in Figures 1(a) and (b). Sizes of the fibers ranged from about $5 \mu \mathrm{m}$ in the fine portion to $150 \mu \mathrm{m}$ in the thick portion. The large nodes formed a spacious shelf and extended fibrous branches in every direction. The major axes were 150 to $250 \mu \mathrm{m}$. The fibers of sponges immersed in dextran solution were larger in diameter than those of sponges without immersion in dextran solution (Figures 2(a) and (b)). Each fiber presented a thick plate with a width of 150-300 $\mu \mathrm{m}$. The fibers of the sponge seemed to be covered with viscous substance. The possibility that the dextran coating on the fiber was preserved under rBMCs seeding and during subcutaneous tissue implantation was shown by SEM observation of sponges that had been kept in MEM for 4 weeks after immersion in dextran solution (Figure 3). However, the surface of the substance on the fiber of sponge just after immersion in dextran solution was smoother than the surface of the sponge stored in MEM.

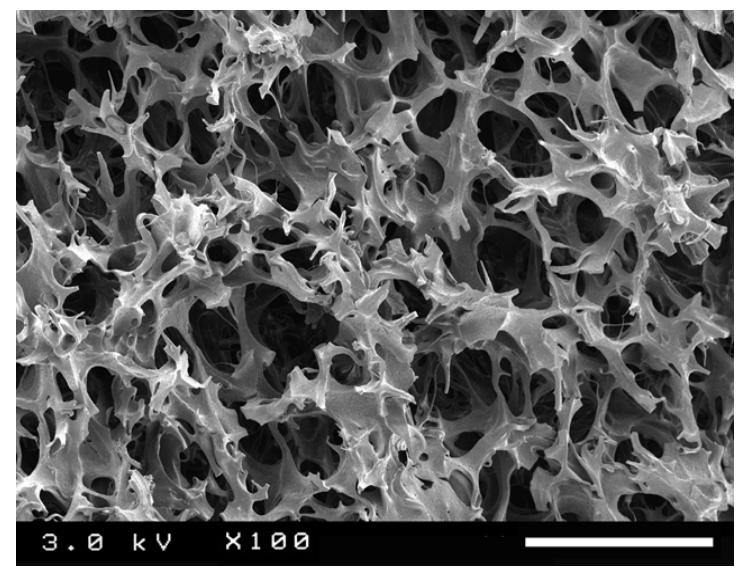

(a)

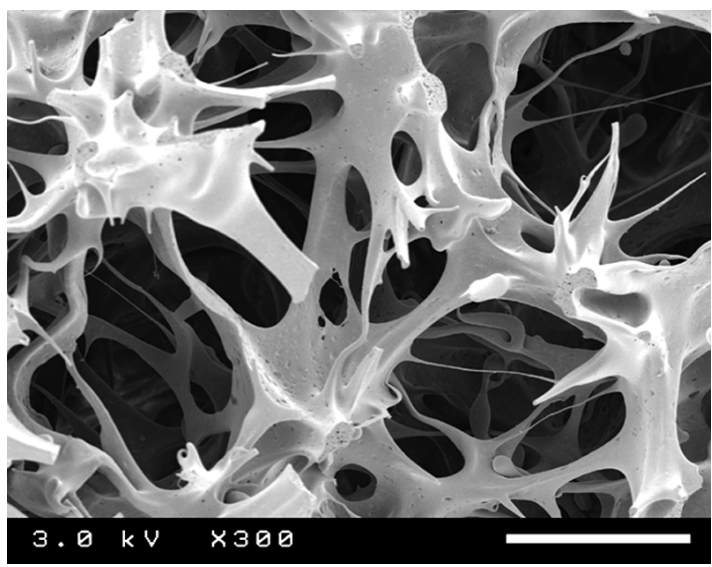

(b)

Figure 1. (a) SEM image of PVF sponge without immersion in dextran solution Fine fibers connected with each other were observed in the interior of the sponge. (Bar: $300 \mu \mathrm{m}$ ); (b) This illustrate shows image of higher magnification of Figure 1(a). Fine fibers were clearly seen. (Bar: $100 \mu \mathrm{m}$ ). 


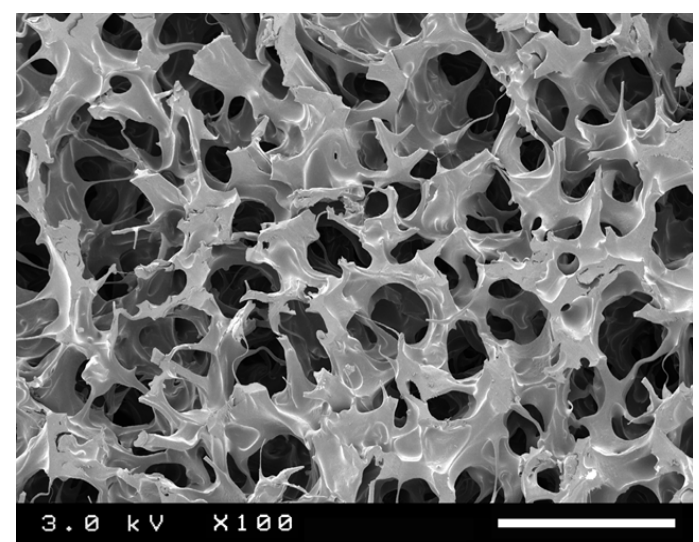

(a)

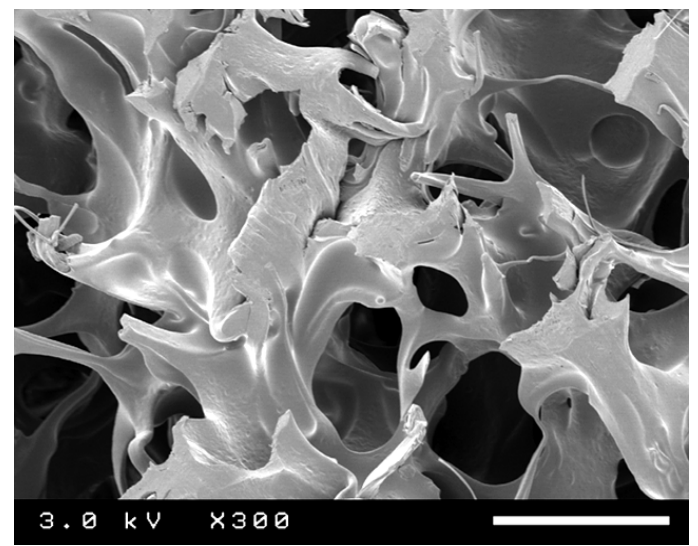

(b)

Figure 2. (a) SEM image of PVF sponge following immersion in the dextran solution. The fibers seemed to be covered with a viscous substance. (Bar: $300 \mu \mathrm{m}$ ); (b) This illustration shows image of higher magnification of Figure 2(a). Dense coating with dextran was seen on the fibers (Bar: $100 \mu \mathrm{m})$.

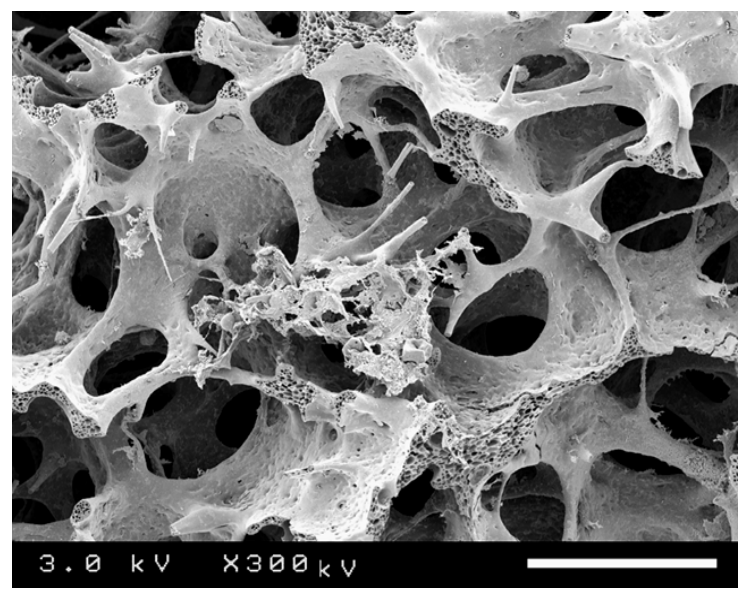

Figure 3. SEM image of dextran-coated PVF sponge After storage in MEM for 4 weeks following immersion in dextran solution (Bar: $100 \mu \mathrm{m})$.

\subsection{Effect of Dextran on Osteogenesis in the PVF Sponge used as a Scaffold in vivo: Histological Examination}

Based on histological findings of PVF scaffold after a 4-week implantation in the rat subcutis, there was no bone recognized in the sponge without immersion in dextran solution prior to seeding of rBMCs as shown in Figure 4. Densely arranged fibrous connective tissue infiltrated the fibers of the sponge. In the sponge with immersion in dextran solution prior to rBMCs seeding, conspicuous osteogenesis was recognized on fibers accompanied by infiltration of connective tissue (Figure 5).

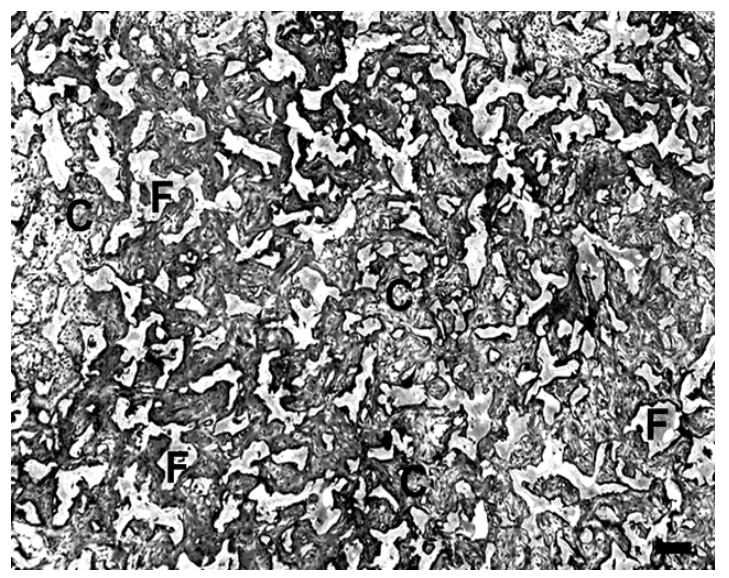

Figure 4. Histological findings of implanted PVF sponge without immersion in dextran solution before implantation. There was no apparent bone in the sponge. Between fibers of the sponge, densely arranged fibrous connective tissue was seen. C: Fibrous tissue infiltrated in the sponge; F: Fiber of sponge (Bar: $200 \mu \mathrm{m}$ ).

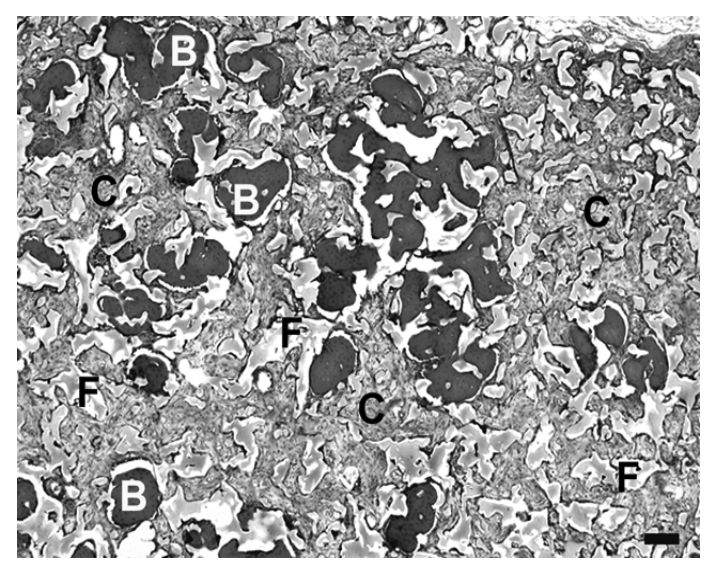

Figure 5. Histological findings of implanted PVF sponge immersed in dextran solution before implantation Conspicuous osteogenesis was recognized among the fibers of sponge. Infiltrated fibrous connective tissue was also seen. B: Bone; C: Fibrous connective tissue infiltrated in the sponge; F: Fiber of sponge (Bar: $200 \mu \mathrm{m}$ ). 


\subsection{Quantity of Osteocalcin in Implanted Sponge with and without Immersion in Dextran Solution: Immunochemical Quantitative Analysis}

In the sponge without immersion in dextran solution before rBMCs seeding and subcutaneous tissue implantation, $9.42 \pm 5.67 \mathrm{ng} / \mathrm{scaffold}$ of osteocalcin was measured. However, $25.28 \pm 5.71 \mathrm{ng} / \mathrm{scaffold}$ of osteocalcin was detected in the sponge immersed in dextran solution. There was a significant difference between the sponges with and without immersion in dextran solution (Figure 6: $p<0.01$ ).

\subsection{Quantity of Calcium in Implanted Sponge with and without Immersion in Dextran Solution: Biochemical Quantitative Analysis}

Quantity of calcium detected in the implanted sponge with immersion in dextran solution before rBMCs seeding was $129.20 \pm 19.69 \mu \mathrm{g} /$ scaffold (Figure 7). In implanted sponge without immersion in dextran solution, detected quantity of calcium was $79.41 \pm 8.69 \mu \mathrm{g} / \mathrm{scaf}$ fold. There was a significant difference between the implanted sponges with and without immersion in dextran solution prior to seeding of rBMCs $(p<0.01)$.

\section{DISCUSSION}

The tooth is classified into an anterior tooth, a canine, a premolar and a molar tooth. Moreover, those are distinguished morphologically about a maxillary or a mandibular tooth, and left or right. Tooth configurations vary, and there are differing origins of hard tissues and pulp that

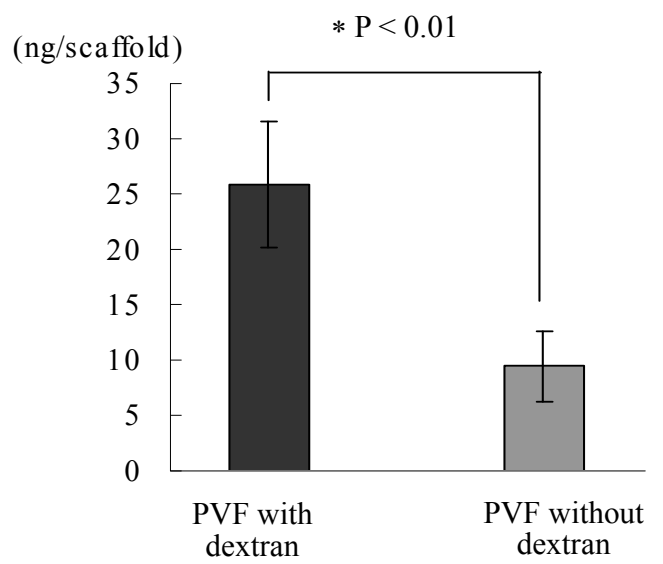

Figure 6. Osteocalcin level of implanted sponges with or without immersion in dextran solution prior to seeding of rBMCs. On comparison between sponges without and with immersion in dextran solution, there was a greater quantity of osteocalcin in sponges with dextran than in those without dextran. Values are means $\pm \mathrm{SD}(\mathrm{n}=3) . * p<0.01$ vs. sponges with immersion in dextran solution.

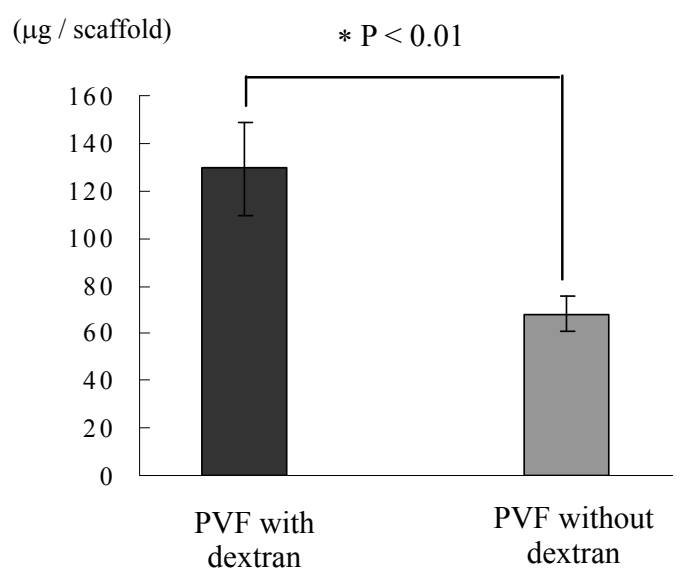

Figure 7. Calcium level of implanted sponges with or without immersion in dextran solution followed by seeding of rBMCs. On comparison between sponges with and without immersion in dextran solution, quantity of calcium was greater in sponges with immersion in dextran solution than in those without immersion in dextran solution. Values are means $\pm \mathrm{SD}(\mathrm{n}=3)$. $* p<0.01$ vs. sponges with immersion in dextran solution.

construct a tooth. Therefore, tooth regeneration is difficult for the complicated configuration [18]. It was reported that a structure similar to a mature tooth including dentine, enamel, cementum and pulp was induced from a tooth germ in vitro [7]. For tooth regeneration, several steps will be required, such as restoration of the defect by regeneration of hard tissue, realization of endothelial and fibrous conjugation to a regenerated root, regeneration of the dentine-pulp complex, and then, complete tooth regeneration.

For restoration of a tooth defect, stem cells should be differentiated into odontoblasts from odontoblast precursor cells in a scaffold. Therefore, it would be desirable for the scaffold to be configurated according to the defect. PVF sponge is considered a desirable scaffold material because it can easily be shaped to the configuration of the defect. PVF scaffold has previously been used for three-dimensional in vivo osteogenic examination [19]. On SEM observation, pores measuring about $100-280 \mu \mathrm{m}$ in diameter were recognized in PVF sponge. It was reported that such a pore size is suitable for osteogenesis in an HA scaffold [20]. This finding suggests that osteogenesis in the PVF sponge is possible. However, there is a conspicuous difference in the internal structures of a hydroxyapatite (HA) scaffold and those of a PVF scaffold. Reticular structure of PVF sponge was shown by SEM findings. Stem cells seeded in PVF sponge may flow out of the sponge with the suspension, while HA scaffold, stem cells may be taken into the 
pores. The PVF sponge is an unfavorable substrate for adhesion of BMCs.

Therefore, for osteogenesis in PVF sponge by subcutaneous tissue implantation in vivo, the sponge should be modified so that seeded stem cells could adhere in the sponge. In fact, it was reported that modification of PVA by extracellular matrix is necessary for adhesion and proliferation of stem cells in the sponge [21,22]. As a result of proliferation and differentiation to osteoblasts of stem cells, bone is formed. In this in vivo study of seeding bone marrow cells in PVF sponge, there was no osteogenesis recognized in the sponge without dextran coating. This finding showed that $\mathrm{rBMCs}$ did not adhere to the construction in the PVF scaffold. PVA having aldehyde groups and hydroxyl groups as functional groups reacts with formalin and produces acetal in the intramolecule of PVA. As a result, it is thought that these functional groups were covered and lost reactivity. PVF sponge without functional group could not be used as a scaffold for osteogenesis by BMCs.

It was reported that intercellular adhesion involves direct binding by cell adhesion molecule in an extracellular matrix or cell membrane $[21,22]$. In addition, the cells are activated by stimulus from cytokine and adhesive high polymer and adhere to the surface of the scaffold [23]. By coating the inner structures of PVF with a highly cytotropic substance, adhesion of seeded stem cells is enabled.

It is known that dextran is a major extracellular matrix and it is a natural macromolecule polysaccharide. Furthermore, dextran shows excellent biocompatibility and adhesiveness to protein and cells [15]. It has also been reported that dextran promotes differentiation of BMCs to osteoblasts [24]. Therefore, rBMCs may adhere to PVF sponge through dextran. It is evident that stable adhesion may occur between PVF sponge and dextran $[25,26]$. Based on the SEM findings in this experiment, it seemed that the internal structures of the PVF sponge were covered with a layer of dextran after immersion in the solution. Osteogenesis was subsequently recognized in the PVF scaffold that had been immersed in dextran solution. These findings show that dextran adhered sufficiently to the internal structure of the sponge and facilitated the attachment of the rBMCs. It was reported that dextran agglutinates BMCs and then promoted adherence of the cells to the pore wall in the scaffold $[27,28]$.

Greater osteogenesis was induced by $10 \mathrm{kDa}$ of dextran in PVF sponge than by higher molecular weight dextran. It is necessary to retain BMCs in the PVF sponge for effective osteogenesis. One method to achieve the purpose appears to be using low-molecularweight dextran to coat the scaffold. It was suggested in this study that coating PVF sponge with low-molecularweight dextran $(10 \mathrm{kDa})$ effectively promoted osteogenesis in the sponge.

\section{CONCLUSIONS}

For regeneration of a tooth defect, in this study, PVF sponge was selected as the scaffold because it could be easily shaped and showed excellent biocompatibility. In addition, it was considered that dextran was useful to promote adhesion of BMCs. In vivo osteogenesis by rBMCs in PVF sponge as a scaffold with dextran coating was examined histologically, biochemically and immunochemically.

The findings obtained from this study were as follows.

1) rBMCs did not adhere to untreated PVF sponge and no bone was formed.

2) The fiber in PVF sponge should be covered with a layer of the dextran by immersion in a solution of $10 \mathrm{kDa}$ dextran.

3) In PVF sponge immersed in dextran solution, the dextran layer coating the inner structure of the sponge persisted after 4 week immersion in MEM.

4) In PVF sponge coated with dextran, osteogenesis by rBMCs was promoted.

\section{REFERENCES}

[1] Yamada, Y., Ueda, M., Naiki, T. and Nagasaka, T. (2004) Tissue-engineered injectable bone regeneration for osseointegrated dental implants. Clinical Oral Implants Research, 15(5), 589-597.

[2] Ohazama, A., Modino, S.A., Miletich, I. and Sharpe, P.T. (2004) Stem-cell-based tissue engineering of murine teeth. Journal of Dental Research, 83(7), 518-522.

[3] Hu, B., Unda, F., Bopp-Kuchler, S., Jimenez, L., Wang, X.J., Haïkel, Y., Wang, S.L. and Lesot, H. (2006) Bone marrow cells can give rise to ameloblast-like cells. Journal of Dental Research, 85(5), 416-421.

[4] Yen, A.H. and Sharpe, P.T. (2008) Stem cells and tooth tissue engineering. Cell Tissue Research, 331(1), 359-372.

[5] Jing, W., Wu, L., Lin, Y., Liu, L., Tang, W. and Tian, W. (2008) Odontogenic differentiation of adipose-derived stem cells for tooth regeneration: Necessity, possibility, and strategy. Medical Hypotheses, 70(3), 540-542.

[6] Duailibi, M.T., Duailibi, S.E., Young, C.S., Bartlett, J.D., Vacanti, J.P. and Yelick, P.C. (2004) Bioengineered teeth from cultured rat tooth bud cells. Journal of Dental Research, 83(7), 523-528.

[7] Zhang, W., Walboomers, X.F., Van Kuppevelt, T.H., Daamen, W.F., Van Damme, P.A. and Bian, Z., (2008) In vivo evaluation of human dental pulp stem cells differentiated towards multiple lineages. Journal of Tissue Engineering and Regenerative Medicine, 2(2-3), 117-125.

[8] Satoyoshi, M., Koizumi, T., Teranaka, T., Iwamoto, T., Takita, H., Kuboki, Y., Saito, S. and Mikuni-Takagaki, Y. (1995) Extracellular processing of dentin matrix protein in the mineralizing odontoblast culture. Calcified Tissue 
International, 57(3), 237-241.

[9] Papagerakis, P., Berdal, A., Mesbah, M., Peuchmaur, M., Malaval, L., Nydegger, J., Simmer, J. and Macdougall, M. (2002) Investigation of osteocalcin, osteonectin, and dentin sialophosphoprotein in developing human teeth. Bone, 30(2), 377-385.

[10] Jeong, W.K., Oh, S.H., Lee, J.H. and Im, G.I. (2008) Repair of osteochondral defects with a construct of mesenchymal stem cells and a polydioxanone/poly (vinyl alcohol) scaffold. Biotechnology and Applied Biochemistry, 49(2), 155-164.

[11] Robinson, B.P., Hollinger, J.O., Szachowicz, E.H. and Brekke, J. (1995) Calvarial bone repair with porous D, L-polylactide. Otolaryngology-Head and Neck Surgery, 112(6), 707-713.

[12] Chang, Y.S., Oka, M., Kobayashi, M., Gu, H.O., Li, Z.L., Nakamura, T. and Ikada, Y. (1996) Significance of interstitial bone ingrowth under load-bearing conditions: A comparison between solid and porous implant materials. Biomaterials, 17(11), 1141-1148.

[13] Nuttelman, C.R., Mortisen, D.J., Henry, S.M. and Anseth, K.S. (2001) Attachment of fibronectin to poly (vinyl alcohol) hydrogels promotes NIH3T3 cell adhesion, proliferation, and migration. Journal of Biomedical Materials Research, 57(2), 217-223.

[14] Cadée, J.A., van Luyn, M.J., Brouwer, L.A., Plantinga, J.A., van Wachem, P.B., de Groot, C.J., den Otter, W. and Hennink, W.E. (2000) In vivo biocompatibility of dextran-based hydrogels. Journal of Biomedical Materials Research, 50(3), 397-404.

[15] Liu, J.M., Haroun-Bouhedja, F. and Boisson-Vidal, C. (2000) Analysis of the in vitro inhibition of mammary adenocarcinoma cell adhesion by sulfated polysaccharides. Anticancer Research, 20(5A), 3265-3271.

[16] Maniatopoulos, C., Sodek, J. and Melcher, A.H. (1988) Bone formation in vitro by stromal cells obtained from bone marrow of young adult rats. Cell and Tissue Research, 254(2), 317-330.

[17] Ohgushi, H., Dohi, Y., Katuda, T., Tamai, S., Tabata, S. and Suwa, Y. (1996) In vitro bone formation by rat marrow cell culture. Journal of Biomedical Materials Research, 32(3), 333-340.

[18] Lemus, D. (1995) Contributions of hetero specific tissue recombinations to odontogenesis. International Journal of Developmental Biology, 39(1), 291-297.

[19] Lewin-Epstein, J., Azaz, B. and Ulmansky, M. (1969) Fate of osteogenic tissue transferred to the subcutaneous area by means of polyvinyl-formal sponge. Israel Journal of Medical Sciences, 5(2), 365-372.

[20] Tsuruga, E., Takita, H., Itoh, H., Wakisaka, Y. and Kuboki, Y. (1997) Pore size of porous hydroxyapatite as the cell-substratum controls BMP-induced osteogenesis. The Journal of Biochemistry, 121(2), 317-324.

[21] Zajaczkowski, M.B., Cukierman, E., Galbraith, C.G. and Yamada, K.M. (2003) Cell-matrix adhesions on poly (vinyl alcohol) hydrogels. Tissue Engineering, 9(3), 525-533.

[22] Tsuji, Y., Yoshimura, N., Aoki, H., Sharov, A.A., Ko, M.S., Motohashi, T. and Kunisada, T. (2008) Maintenance of undifferentiated mouse embryonic stem cells in suspension by the serum- and feeder-free defined culture condition. Developmental Dynamics, 237(8), 2129-2138.

[23] Wang, Y.W., Wu, Q. and Chen, G.Q. (2003) Reduced mouse fibroblast cell growth by increased hydrophilicity of microbial polyhydroxyalkanoates via hyaluronan coating. Biomaterials, 24(25), 4621-4629.

[24] Li, D., Dai, K. and Tang, T. (2008) Effects of dextran on proliferation and osteogenic differentiation of human bone marrow-derived mesenchymal stromal cells. Cytotherapy, 10(6), 587-596.

[25] Cascone, M.G., Maltinti, S., Barbani, N. and Laus, M. (1999) Effect of chitosan and dextran on the properties of poly (vinyl alcohol) hydrogels. Journal of Materials Science: Materials in Medicine, 10(7), 431-435.

[26] Thébaud, N.-B., Pierron, D., Bareille, R., Le Visage, C., Letourneur, D. and Bordenave, L. (2007) Human endothelial progenitor cell attachment to polysaccharidebased hydrogels: A pre-requisite for vascular tissue engineering. Journal of Materials Science: Materials in Medicine, 18(2), 339-345.

[27] Noble, B.S., Dean, V., Loveridge, N. and Thomson, B.M. (1995) Dextran sulfate promotes the rapid aggregation of porcine bone-marrow stromal cells. Bone, 17(4), 375-382.

[28] Lévesque, S.G., Lim, R.M. and Shoichet, M.S. (2005) Macroporous interconnected dextran scaffolds of controlled porosity for tissue-engineering applications. Biomaterials, 26(35), 7436-7446. 